\title{
Dose optimisation for intraoperative cone-beam flat-detector CT in paediatric spinal surgery
}

\author{
Asger Greval Petersen • Søren Eiskjær • Jon Kaspersen
}

Received: 11 July 2011 /Revised: 2 February 2012 / Accepted: 12 February 2012 /Published online: 6 June 2012

(C) The Author(s) 2012. This article is published with open access at Springerlink.com

\begin{abstract}
Background During surgery for spinal deformities, accurate placement of pedicle screws may be guided by intraoperative cone-beam flat-detector $\mathrm{CT}$.

Objective The purpose of this study was to identify appropriate paediatric imaging protocols aiming to reduce the radiation dose in line with the ALARA principle.

Materials and methods Using O-arm ${ }^{\circledR}$ (Medtronic, Inc.), three paediatric phantoms were employed to measure $\mathrm{CTDI}_{\mathrm{w}}$ doses with default and lowered exposure settings. Images from 126 scans were evaluated by two spinal surgeons and scores were compared (Kappa statistics). Effective doses were calculated. The recommended new low-dose 3-D spine protocols were then used in 15 children.

Results The lowest acceptable exposure as judged by image quality for intraoperative use was $70 \mathrm{kVp} / 40 \mathrm{mAs}, 70 \mathrm{kVp} /$ $80 \mathrm{mAs}$ and $80 \mathrm{kVp} / 40 \mathrm{mAs}$ for the 1-, 5- and 12-year-oldequivalent phantoms respectively (kappa $=0,70)$. Optimised dose settings reduced $\mathrm{CTDI}_{\mathrm{w}}$ doses $89-93 \%$. The effective dose was $0.5 \mathrm{mSv}$ (91-94,5\% reduction). The optimised protocols were used clinically without problems.

Conclusions Radiation doses for intraoperative 3-D CT using a cone-beam flat-detector scanner could be reduced at least $89 \%$ compared to manufacturer settings and still be used to safely navigate pedicle screws.
\end{abstract}

Keywords O-arm · Paediatric spine · Preoperative CT scan · Radiation dose

A. G. Petersen $(\bowtie)$

Department of X-ray Physics, Region of Northern Jutland,

Broenderslev, Denmark

e-mail: asgp@rn.dk

S. Eiskjær $\cdot$ J. Kaspersen

The Spinal Unit, Department of Orthopaedic Surgery,

Aalborg University Hospital,

Aalborg, Denmark

\section{Introduction}

It is well-documented that radiographic examinations for spinal deformity during childhood increase the lifetime risk of cancer, particularly breast cancer [1,2]. It follows that precautions need to be taken to reduce radiation burden.

New technologies have advanced surgery for spinal deformities. The use of pedicle screws requires accurate placement to avoid damage to the spinal cord and the large vessels in front of the spine. To secure the correct placement of pedicle screws, intraoperative imaging is imperative. For many years, fluoroscopy was the only available intraoperative imaging modality. However, in the last two decades, navigation based on preoperative CT has been developed. However, it is not widely used, possibly due to the timeconsuming registration process (coupling of the preoperative CT with patient anatomy) of up to $15-20 \mathrm{~min}$ per vertebra making it almost impossible to use in spine deformity surgery with instrumentation of $10-15$ vertebrae in a single operation. On the other hand, the need for navigation is most pressing in young patients who have both deformed and small pedicles.

Intraoperative cone-beam flat-detector X-ray systems have changed spinal surgery and are rapidly being implemented worldwide. These provide both 2-D fluoroscopic and 3-D images, which when coupled to a navigation system add significant value to surgical outcomes [3-6]. With such a system, the registration process is fast and navigation can be performed in four to six vertebrae before a new 3-D scan is needed. The drawbacks are the price (scanner and essential navigation system, approximately $€ 700,000$ in 2012) and the increased radiation burden.

According to Zhang et al. [7], the patient dose delivered by the scanner in default mode is equivalent to $0.5-0.6$ times the dose delivered by a conventional 64-slice CT-scanner. Usually at least two to three scans are required during 
surgery for a spinal deformity. Other authors $[8,9]$ have said the resultant dose is associated with increased cancer risk. On the basis of estimates from the United States [8], it is thought that in children younger than 15 years approximately $80-90$ per $100,000 \mathrm{CT}$ examinations attribute to cancer mortality.

Our aim was to identify appropriate intraoperative exposure settings for children for a cone-beam flat-detector system, aiming to reduce the radiation dose.

\section{Materials and methods}

\section{Scanner}

The O-arm ${ }^{\circledR}$ (Medtronic, Inc.) cone-beam flat-detector system was used. The system has an O-ring type gantry and an $\mathrm{X}$-ray tube equivalent to $32 \mathrm{~kW}$, and a X-ray filter of $4 \mathrm{~mm}$ Al. The flat-panel has an amorphous silicon-based detector of $30 \mathrm{~cm} \times 40 \mathrm{~cm}$ with a $0.194-\mathrm{mm}$ pixel pitch. The system can be configured in 2-D fluoroscopic mode or 3-D mode. In this study, only 3-D mode was used and only the lowdefinition mode. In the low-definition mode, 192 single images (compared to 392 images in high-definition mode) of slice thickness $0.833 \mathrm{~mm}$ were recorded in a 360-degree rotation of the detector and the radiation source with an image matrix of $512 \times 512$. The time for image acquisition was $13 \mathrm{~s}$ with a beam on-time of $3.91 \mathrm{~s}$. The sourceto-isocentre distance of the $\mathrm{O}$-arm was $64.7 \mathrm{~cm}$ and the source-to-detector distance $116.8 \mathrm{~cm}$. The collimated Xray beam was $22.18 \times 16.62 \mathrm{~cm}$ and the $3-\mathrm{D}$ reconstructed volume was $20 \mathrm{~cm} \times 15 \mathrm{~cm}$.

Besides the 16 default imaging protocols (head, chest, abdomen and extremity applied to small, medium, large and extra large patients, respectively), the O-Arm allows manual adjustment of $\mathrm{kVp}$ and $\mathrm{mA}$. With the manual setting, the $\mathrm{kVp}$ can be varied between 50 and 120 with $1-\mathrm{kVp}$ intervals, and the $\mathrm{mA}$ can be varied between 10 and 120 in predefined steps.

The manufacturer's advice (personal communication) for abdominal imaging is to use the default values for small (waist circumference 12-26 cm) or the default values for medium (waist circumference 20-34 cm).

\section{Phantoms}

The studies were conducted using polymethyl-methacrylate (PMMA) phantoms to estimate patient dose equivalence. Four cylindrical PMMA phantoms were made with diameters of $10 \mathrm{~cm}, 16 \mathrm{~cm}, 24 \mathrm{~cm}$ and $32 \mathrm{~cm}$ (Fig. 1). The $10-\mathrm{cm}$ PMMA would be equivalent to the body of a child $<1$ year old, and the phantoms of $16 \mathrm{~cm}, 24 \mathrm{~cm}$ and $32 \mathrm{~cm}$ would be equivalent to the body of a 5-year old, 12-year-old and an adult, respectively $[3,10]$. All phantoms were $15 \mathrm{~cm}$ long

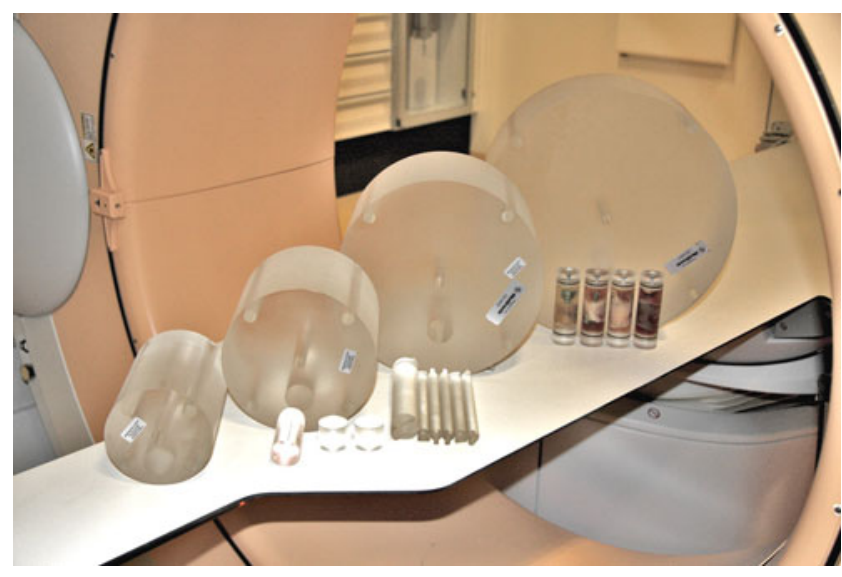

Fig. 1 Polymethyl-methacrylate (PMMA) phantoms with diameters $10-32 \mathrm{~cm}$ that were scanned together with inserts of bone specimens, solid PMMA rods and a tungsten wire

and had standard holes for CTDI dosimetry at the centre and at the perimeter but were also made with a $3-\mathrm{cm}$ cylindrical hole through the phantom in a radial distance from the perimeter corresponding with the position of the spine in a patient of the same size. In this hole, four samples made from human femoral neck (Fig. 2), three of which also contained pedicle screws, were placed and scanned one at a time in the centre of the phantom with the remaining holes filled with solid PMMA rods. The locations of the screws with respect to the cortical edge of the bone were chosen to match clinically realistic scenarios.

\section{Dose measurements}

The dose to the patient was expressed as $\mathrm{CTDI}_{\mathrm{w}}$ and calculated from the dose measured in the PMMA cylinders in the periphery and centre with a $100-\mathrm{mm}$ pencil ion chamber with all other holes filled with solid PMMA rods. The CTDI ${ }_{w}$ was measured for each phantom size using both the default and the optimised values for the setting of $\mathrm{kVp}$ and $\mathrm{mA}$. The absorbed doses of radiosensitive organs and total effective doses were calculated for each phantom size, using both the default and the optimised values for $\mathrm{kVp}$ and $\mathrm{mAs}$. The calculations were performed with the PCXMC Monte Carlo dose simulation program version 2.0 (STUK - Radiation and Nuclear Safety Authority, Helsinki, Finland) using the ICRP 103 tissue weighting-factors [11]. To perform this calculation, the PCXMC program requires measurements of the incident air kerma at the surface of each phantom without backscatter factor. This was measured at the isocentre with the $100-\mathrm{mm}$ pencil ion chamber and calculated for the surface of each phantom using the inverse square law. To reduce the computation time with PCXMC, the 360-degree arc was divided into 12 parts of 30 degrees. The absorbed doses to the radiosensitive organs and total effective doses were calculated by summing the contributions of each of the 12 dose calculations. 
Fig. 2 Design of both polymethyl-methacrylate (PMMA) cylinders and the four inserts of bone bank bones from patients having undergone hip arthroplasty and pedicle screws: (lower inserts from left to right) pure bone, screw parallel to cortex, screw just reaching the cortex, screw just penetrating cortex

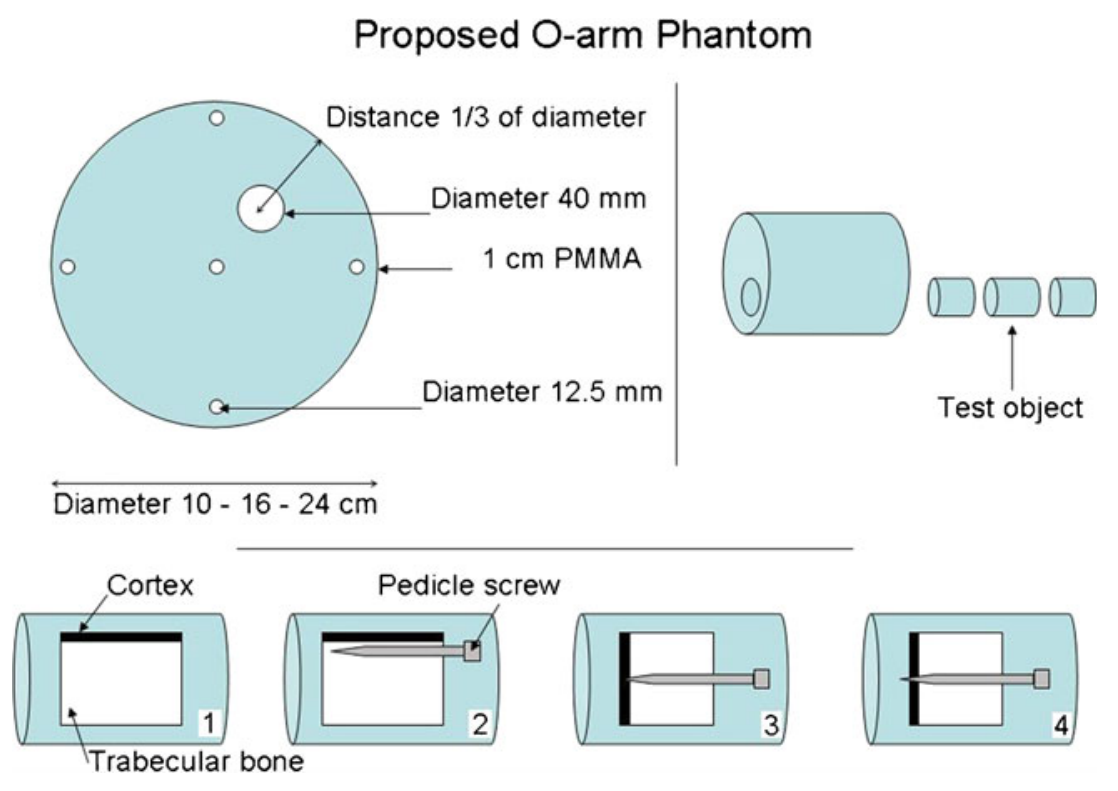

Image quality assessment

Signal-to-noise ratio (SNR) and contrast-to-noise ratio (CNR) were measured. SNR was calculated as $\mathrm{S} 1 / \sigma 1$, where $\mathrm{S} 1$ represents the mean pixel value within a region of interest (ROI) in the PMMA phantom with all PMMA rods inserted at the position of the bone samples and $\sigma 1$ represents the standard deviation of pixel values within the same ROI. CNR was estimated as $|\mathrm{S} 2-\mathrm{S} 1| / \sigma 1$, where $\mathrm{S} 2$ is the mean pixel value in the pure bone sample. For this purpose, ImageJ version 1.32 (http://rsb.info.nih.gov/ij/) was used.

The subjective image quality of all phantom images with pedicle screws (126 scans) was evaluated independently by two spinal surgeons, both with more than 10 years of experience in spinal surgery and intraoperative imaging. The image quality was deemed adequate if the outlines of the bones were visible and if it was possible to discern whether the screw penetrated the bone. If the outlines of the bone sample and the screw position could be visualised with certainty, the image quality was deemed as adequate. In all other cases, the image quality was deemed inadequate. Interobserver agreement was measured with Kappa statistic $[12,13]$.

\section{Dose optimisation}

The scans started with the factory default settings, followed by a series of scans with decreasing $\mathrm{mA}$ until the lowest possible tube current of $10 \mathrm{~mA}$ was reached. If image quality was still acceptable, additional scans were acquired at $10 \mathrm{~mA}$ while reducing $\mathrm{kV}$ until an unacceptable image quality was achieved. The scan parameters with the lowest dose to the phantom where the image quality in all four bone samples were accepted were recorded as the suggested optimum low-dose settings for that specific phantom size. Scans were then acquired with all holes filled with solid PMMA rods to measure image noise and dose.

After institutional review board approval, the recommended new low-dose 3-D spine protocol was tested in clinical practice in 15 children (10 females) with severe deformities in whom it would not have been possible to place pedicle screws without navigation. This would otherwise require conventional preoperative CT with a higher dose. Only the $16-\mathrm{cm}$ and $24-\mathrm{cm}$ protocols were used. The average age was 11.5 years (range, 2-17 years). An average of 9.7 vertebrae were scanned (range, 3-16) using an average of 2.5 acquisitions (range, 1-4), as shown in Table 1.

\section{Results}

As expected, SNR and CNR decreased nonlinearly with decreasing radiation dose (Fig. 3). SNR and CNR at lowest acceptable dose decrease with increasing phantom size. Therefore, patient size is a crucial factor when choosing the values of SNR and CNR for lowest acceptable image quality.

Table 2 compares the preset and optimised protocols and dose values. For both the $10-\mathrm{cm}$ and the $16-\mathrm{cm}$ phantoms, the optimised dose was compared with the dose of the standard small chest protocol. For the $24-\mathrm{cm}$ phantom, the optimised dose was compared with dose of the standard medium chest protocol. All optimised settings yielded at least a $89 \%$ reduction in dose, with the $10-\mathrm{cm}$ protocol yielding a $93 \%$ dose reduction as shown in Tables 2 and 3 . This was corroborated when the effective dose was calculated with effective dose values approximately $0.5 \mathrm{mSv}$ for the optimised protocols and effective dose values 12-19 times higher for the default protocols as shown in Table 4. 
Table 1 Patient characteristics, number of scans, protocols and radiation doses for 15 children undergoing corrective spinal surgery using a cone-beam scanner with radiation-dose optimised exposure for guiding pedicle screw placement

\begin{tabular}{|c|c|c|c|c|c|c|c|c|}
\hline Patient & $\begin{array}{l}\text { Sex; age at } \\
\text { surgery } \\
\text { (years) }\end{array}$ & Diagnosis & $\begin{array}{l}\text { Number of } \\
\text { levels }\end{array}$ & $\begin{array}{l}\text { Patient height } \\
(\mathrm{cm}) / \text { weight } \\
(\mathrm{kg})\end{array}$ & $\begin{array}{l}\text { Number of } \\
\text { intraoperative } \\
\text { scans }\end{array}$ & $\begin{array}{l}\mathrm{DLP} \\
\mathrm{mGy} \cdot \mathrm{cm}^{\mathrm{a}}\end{array}$ & $\begin{array}{l}\text { Scan protocol exposure } \\
\text { settings } \\
\mathrm{kVp} / \mathrm{mA}\end{array}$ & Instrumentation \\
\hline 1 & M, 17 & Idiopathic scoliosis & 12 & $185 / 76$ & 3 & 94 & $80 / 20$ & Conventional $^{\mathrm{b}}$ \\
\hline 2 & $\mathrm{~F}, 2$ & Hemivertebra & 3 & $82 / 11$ & 1 & 17 & $80 / 10$ & Conventional $^{\mathrm{b}}$ \\
\hline 3 & $\mathrm{M}, 13$ & $\begin{array}{l}\text { Neuromuscular } \\
\text { scoliosis }\end{array}$ & 16 & $159 / 31$ & 4 & 80 & $70 / 20$ & Conventional $^{\mathrm{b}}$ \\
\hline 4 & $\mathrm{~F}, 15$ & Idiopathic scoliosis & 7 & $158 / 45$ & 2 & 65 & $80 / 20$ & Conventional $^{\mathrm{b}}$ \\
\hline 5 & F, 15 & Idiopathic scoliosis & 9 & $162 / 52$ & 2 & 40 & $70 / 20$ & Conventional $^{\mathrm{b}}$ \\
\hline 6 & $\mathrm{M}, 12$ & $\begin{array}{l}\text { Neuromuscular } \\
\text { scoliosis }\end{array}$ & 15 & $152 / 32$ & 3 & 60 & $70 / 20$ & Conventional $^{\mathrm{b}}$ \\
\hline 7 & M, 6 & Infantile scoliosis & 4 & $99 / 13$ & 2 & 65 & $80 / 20$ & Growth rod \\
\hline 8 & $\mathrm{~F}, 5$ & Infantile scoliosis & 8 & $109 / 16$ & 3 & 86 & $80 / 10$ & Conventional $^{\mathrm{b}}$ \\
\hline 9 & F, 14 & Idiopathic scoliosis & 6 & $161 / 48$ & 2 & 40 & $70 / 20$ & Conventional $^{\mathrm{b}}$ \\
\hline 10 & $\mathrm{~F}, 12$ & $\begin{array}{l}\text { Neuromuscular } \\
\text { scoliosis }\end{array}$ & 13 & $121 / 28$ & 4 & 80 & $70 / 20$ & Conventional $^{\mathrm{b}}$ \\
\hline 11 & $\mathrm{~F}, 11$ & $\begin{array}{l}\text { Neuromuscular } \\
\text { scoliosis }\end{array}$ & 11 & $150 / 43$ & 2 & 60 & $80 / 10,70 / 20$ & Conventional $^{\mathrm{b}}$ \\
\hline 12 & $\mathrm{M}, 14$ & $\begin{array}{l}\text { Neuromuscular } \\
\text { scoliosis }\end{array}$ & 16 & $165 / 40$ & 4 & 80 & $70 / 20$ & Conventional $^{\mathrm{b}}$ \\
\hline 13 & $\mathrm{~F}, 14$ & Idiopathic scoliosis & 10 & $175 / 75$ & 2 & 40 & $70 / 20$ & Conventional $^{\mathrm{b}}$ \\
\hline 14 & $\mathrm{~F}, 8$ & $\begin{array}{l}\text { Spondylolisthesis } \\
\text { gr. } 4\end{array}$ & 4 & $134 / 28$ & 1 & 16 & $80 / 10$ & Conventional $^{\mathrm{b}}$ \\
\hline 15 & F, 14 & Idiopathic scoliosis & 11 & $171 / 60$ & 3 & 97 & $80 / 10$ & Conventional $^{\mathrm{b}}$ \\
\hline
\end{tabular}

a According to the manufacturer

${ }^{\mathrm{b}}$ Conventional segmental instrumentation with pedicle screws and rods

The observers agreed that the lowest acceptable dose for intraoperative imaging was $70 \mathrm{kVp} / 40 \mathrm{mAs}$ for the 1 -yearold-equivalent phantom $(10 \mathrm{~cm}), 70 \mathrm{kVp} / 80 \mathrm{mAs}$ for the 5 year-old-equivalent phantom $(16 \mathrm{~cm})$ and $80 \mathrm{kVp} / 40 \mathrm{mAs}$ for the 12-year-old-equivalent phantom $(24 \mathrm{~cm})$. Figure 4 shows examples of images of pedicle bone implants with minimal penetration at different dose settings.

The interobserver agreement for all scans had a kappa $=0,70$ (substantial agreement [14]). For the 10-cm, 16-cm and 24-cm phantoms, kappa was $0.64,0.72$ and 0.70 , respectively, also indicating substantial agreement.

In all 15 operations using the optimised setting, the spinal surgeon achieved adequate intraoperative imaging with the cone-beam flat-detector scanner followed by navigation using the Stealth system (Stealth Station ${ }^{\circledR}$, Medtronic, Minneapolis, USA). Figure 5 shows examples of intraoperative images with different dose settings with and without pedicle screws. The same protocol was used both for the thoracic and abdominal regions. In none of the cases was control CT done postoperatively because of suspected misplacement of screws or neurological deterioration. Conventional radiographs showed satisfactory placement of all screws and the neurological status was unchanged for all children. Spinal cord monitoring (sensory evoked potentials (SEP) and motor evoked potentials
(MEP)) did not indicate damage to the spinal cord or the spinal nerves in any of the children.

\section{Discussion}

The phantom model allowed a systematic evaluation of different dose settings from the highest to the lowest possible. It also allowed different bone inserts containing pedicle screws to be evaluated with regard to image quality. This is especially important as the cornerstone of image guidance during pedicle screw insertion is the ability to clearly identify the cortex relative to the pedicle screw. Streak artefacts from metallic implants are a major concern, and any realistic model needs to incorporate this. Our phantom model could only be used to evaluate 90 -degree perforations of the cortex due to the small size of the bone samples. However, to compensate for this limitation, for the sample with the perforating screw, the perforation was made as small as possible.

The $\mathrm{CTDI}_{100}$ does not measure the actual absorbed dose by the individual patient but should be considered an index for comparisons. The homogeneous PMMA does not simulate the different tissue types and heterogeneities in vivo. 
a

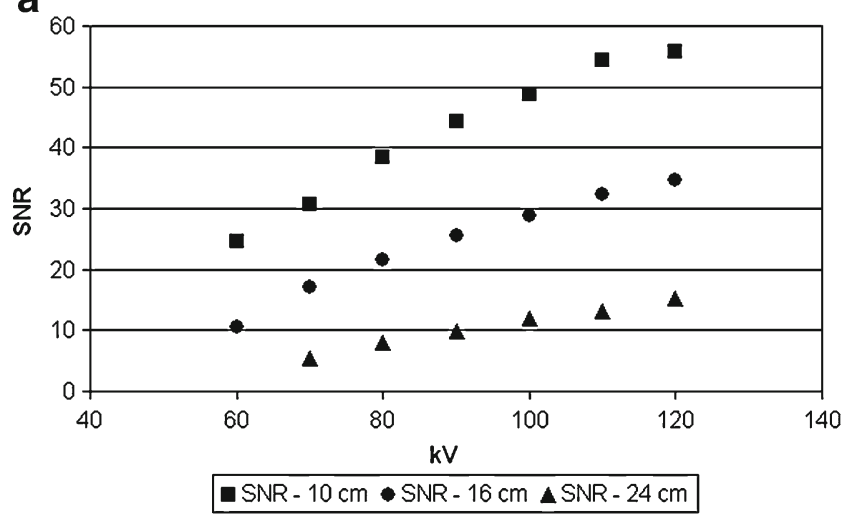

b



Fig. 3 Objective image quality parameters for different phantom diameters $(10 \mathrm{~cm}, 16 \mathrm{~cm}$ and $24 \mathrm{~cm})$ at constant tube current. a Signal-to-noise ratio (SNR) against $\mathrm{kV}$. b Contrast-to-noise ratio (CNR) against $\mathrm{kV}$

The $\mathrm{CTDI}_{100}$ will underestimate the radiation dose because the $100-\mathrm{mm}$ pencil ion chamber only partly covers the collimated beam width. For X-ray beams wider than $40 \mathrm{~mm}$, a pencil chamber longer than $100 \mathrm{~mm}$ is required. The $\mathrm{CTDI}_{\mathrm{w}}$ will underestimate the ideal $\mathrm{CTDI}_{\mathrm{w}}$ with approximately $20 \%$ at a collimated beam width of $20 \mathrm{~mm}$ [15]. Dixon [16] has described an alternative method to directly measure the dose at the central scan plane using a small ion chamber.

The patient dose of the cone-beam system relative to CT has been described by Zhang et al. [7], who showed that with identical techniques $(\mathrm{kVp}, \mathrm{mAs}$, etc.) and with the same scan length, the cone-beam system in 3-D mode delivered approximately half the radiation dose of a 64-slice CT scanner. Their use of a Farmer ion chamber gave a more correct estimation of patient dose compared to the 100-mm ion chamber used in our study for dose comparison as it could be used to directly measure the point dose at the centre of the scan length. Differences between cone-beam systems and $\mathrm{CT}$ are to be expected due to differences in source-toisocentre distance (SID). The SID of the cone-beam system was $64.7 \mathrm{~cm}$ while the SID of the 64-slice CT scanner in question was $57.1 \mathrm{~cm}$. This accounts for approximately $29 \%$ of the dose difference [7]. Second, there is a difference in fan beam angle. The cone-beam system has an angle of approximately 20 degrees, and the CT scanner approximately 45 degrees. This leads to less peripheral radiation dose measurements for the cone-beam system because the ion chamber is outside the beam during parts of the scan [7]. The differences in over beaming between the cone-beam system and the CT scanner will account for a slight dose reduction in favour of the cone-beam system [7].

Would a vertebra have been a better bone sample for the phantom part of the study? This would without doubt have better represented the normal anatomy. The cortical thickness of the femoral head is greater than the cortical thickness of the vertebra, and this would have influenced the accuracy of the imaging representation [17]. A more accurate model would probably improve the surgeons' ability to discern whether a screw was placed correctly. The bone mineral density of children and adolescents changes significantly with age $[18,19]$. The bone samples used here were acquired from the local bone bank. The femoral necks used in this study were obtained solely from patients undergoing hip arthroplasty, and these patients are in general not osteoporotic $[18,21]$. Mean BMD for a hip arthroplasty patient is approximately $1 \mathrm{~g} / \mathrm{cm}^{2}$ with slight variation in several recent studies [20,21]. Lumbar spine BMD in children varies from approximately $0.6 \mathrm{~g} / \mathrm{cm}^{2}$ (age 5 years) to $1.0 \mathrm{~g} / \mathrm{cm}^{2}$ (age 17 years) with much greater variation $[18,19]$. A single bone sample would not model the bone density of any childhood vertebra since BMD changes with age. In this series (no BMD measurements), the probable difference
Table 2 Radiation doses at default exposure settings for different sizes of body/anatomy ( $L$ large, $M$ medium, $S$ small) and at exposures optimised for low-dose 3-D paediatric spine imaging with dose reduction factors for all phantom sizes

\begin{tabular}{llrrrrl}
\hline Phantom diameter $(\mathrm{cm})$ & Protocol & $\mathrm{kV}$ & $\mathrm{mA}$ & $\mathrm{mAs}$ & $\mathrm{CTDI}_{\mathrm{w}}$ (mGy) & Dose reduction, \% \\
\hline 32 & $\mathrm{~L}$ & 120 & 50 & 200 & 11.3 & \\
24 & $\mathrm{M}$ & 120 & 40 & 160 & 14.5 & \\
24 & Low dose & 70 & 20 & 80 & 1.6 & 89.2 \\
16 & $\mathrm{~S}$ & 120 & 32 & 128 & 14.4 & 89.4 \\
16 & Low dose & 80 & 10 & 40 & 1.5 & \\
10 & $\mathrm{~S}$ & 120 & 32 & 128 & 16.6 & 93.0 \\
10 & Low dose & 70 & 10 & 40 & 1.2 & \\
\hline
\end{tabular}


Table 3 Scan protocols for a 1year-old-equivalent phantom with dose reduction achieved and scoring of image quality

\begin{tabular}{llrlrrrl}
\hline $\begin{array}{l}\text { Phantom diameter } \\
(\mathrm{cm})\end{array}$ & $\begin{array}{l}\text { Scan } \\
\text { protocol }\end{array}$ & $\mathrm{kV}$ & $\mathrm{mA}$ & $\mathrm{mAs}$ & $\begin{array}{l}\mathrm{CTDI}_{\mathrm{w}} \\
(\mathrm{mGy})\end{array}$ & Dose reduction, \% & $\begin{array}{l}\text { Image quality } \\
\text { scoring }\end{array}$ \\
\hline 10 & 1 & 120 & 32 & 128 & 16.59 & 0 & $\mathrm{OK}$ \\
10 & 2 & 120 & 20 & 80 & 10.41 & 37.3 & $\mathrm{OK}$ \\
10 & 3 & 120 & 10 & 40 & 5.47 & 67.0 & $\mathrm{OK}$ \\
10 & 4 & 100 & 10 & 40 & 3.39 & 79.6 & $\mathrm{OK}$ \\
10 & 5 & 80 & 10 & 40 & 1.81 & 89.1 & $\mathrm{OK}$ \\
10 & 6 & 70 & 10 & 40 & 1.15 & 93.1 & OK \\
10 & 7 & 60 & 10 & 40 & 0.69 & 95.8 & Not OK \\
\hline
\end{tabular}

between BMD in the femoral neck of elderly patients with hip arthrosis and children's spines would tend to underestimate the radiation dose needed to satisfactorily visualise the correct placement of pedicle screws in young children because the BMD is considerably lower in children 1-9 years of age. However, this did not cause any problems for the implementation of the optimised protocol. For most children who undergo corrective spinal surgery (10-17 years of age), BMD of the lumbar spine is probably not very different from that of the bone samples used in our study.

A substantial number of pedicle screws are misplaced when navigation is not used. The rate of pedicle perforation varies between $10 \%$ and $40 \%$ [22-24]. Our own data (unpublished) for the first 30 children where the screws were placed under fluoroscopic guidance and then positioncontrolled with volumetric imaging indicate that approximately $8 \%$ of a total of 424 screws were misplaced (according to the Ohlin classification [24]) and 1\% of screws had to be repositioned or removed. Since we started using the cone-beam flat-panel detector scanner in 2008, we have not had any nerve or spinal cord damage caused by misplaced screws. This has been corroborated by several other studies [25-27]. The cost-benefit of navigation is welldocumented [5]. It is also well-documented that 3-D techniques are superior to other techniques used for navigation $[22,23]$. Some surgeons use freehand techniques relying only on anatomical landmarks. The anatomy of the scoliotic spine in children is highly variable, the pedicles often very small and the deformity often great. Freehand techniques are only feasible for a few very talented and experienced spinal deformity surgeons. Most surgeons would prefer to use some kind of intraoperative imaging guidance. The number of misplaced screws in degenerative adult lumbar spines using freehand techniques was significantly greater than the number of misplaced screws placed following a 3-D scan with subsequent navigation [27]. According to the manufacturers, the radiation dose of one 3-D scan equals that of $35 \mathrm{~s}$ of fluoroscopy [7]. Fluoroscopy time has been calculated to be approximately 7-20 s per screw [28-31]. With an average ten screws per child in our case study, this equals 68-193 s of fluoroscopy time per operation, or the equivalent of two to six volumetric scans, representing a higher radiation dose compared to our case study. One also needs to take into account that the pedicle screw misplacement rate is significantly reduced when navigation is based on 3-D imaging [22-24]. The misplacement rate is even higher in children, which further strengthens the case for using volumetric guidance [27].

There are currently few alternatives to the system used in our study $[32,33]$. Other available systems are slower and only two to three spinal levels can be imaged simultaneously, resulting in an imaging time of 8-9 min (as compared to 1 min of discontinuation time for the described system). Other low-dose systems like EOS [34, 35] or the system described by Abul-Kassim et al. [24] cannot be used intraoperatively. The EOS system in particular can only be used for standing or sitting patients [34, 35].

Abul-Kasim et al. [36] have also tried to optimise the radiation exposure and image quality of the same system used in our study. Using a completely different model
Table 4 Estimated effective doses at default exposure settings for different sizes of body/ anatomy ( $L$ large, $M$ medium, $S$ small) and at exposures optimised for 3-D paediatric spine imaging with dose reduction factors for all phantom sizes

\begin{tabular}{llrrrrl}
\hline Phantom diameter $(\mathrm{cm})$ & Protocol & $\mathrm{kV}$ & $\mathrm{mA}$ & $\mathrm{mAs}$ & Effective dose (mSv) & Dose reduction, \% \\
\hline 24 & $\mathrm{M}$ & 120 & 40 & 160 & 8.3 & \\
24 & Low dose & 70 & 20 & 80 & 0.4 & 94.7 \\
16 & $\mathrm{~S}$ & 120 & 32 & 128 & 6.3 & \\
16 & Low dose & 80 & 10 & 40 & 0.5 & 91.7 \\
10 & $\mathrm{~S}$ & 120 & 32 & 128 & 5.8 & 92.2 \\
10 & Low dose & 70 & 10 & 40 & 0.5 & \\
\hline
\end{tabular}



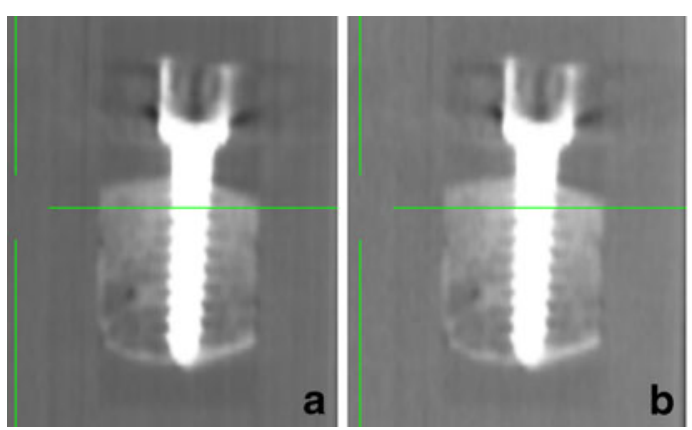

Fig. 4 Scan of a 10-cm polymethyl-methacrylate phantom with bone insert at default exposure settings $120 \mathrm{kVp} / 128 \mathrm{mAs}$ (a), and at $120 \mathrm{kVp} / 40 \mathrm{mAs}(\mathbf{b}), 80 \mathrm{kVp} / 40 \mathrm{mAs}$ (c), at the lowest exposure for

(anthropomorphic adult chest model and porcine spine with pedicle screws), they arrive at almost the same dose settings as we recommend. The pedicle perforation rate in the porcine spine model was higher than the perforation rate simulated in our model, which may explain some difference in observer agreement at low dose.

The cylindrical-equivalent diameter of a body is defined as the diameter of the cylinder that the body would form if laterally compressed into a cylinder of equal cross-sectional area. This definition should not be confused with the definition of patient-equivalent cylinder based on the patient's weight and height as suggested by The Danish National Board of Health [37]. The equivalent diameter may be calculated as $d=2 \sqrt{a b}$ where $a$ and $b$ are the minor and major diameters of the ellipse. Note that the circumference of the patient-equivalent circle and the elliptic cross-section of the patient are not equal, and can therefore only estimate the diameter of the patient equivalent cylinder with an error of $10-15 \%$ depending on the eccentricity of the patient. Given that the difference in the diameter between the patient equivalent phantoms is about $50 \%$, it might be sufficient to use the circumference to calculate the diameter of the patient to select the appropriate protocol.

The phantoms in our study simulated the lumbar anatomy. The results may therefore not adequately reflect the dose reduction achievable in the thorax. Based on the level acceptable image quality, $70 \mathrm{kVp} / 40 \mathrm{mAs}$ (d) and below acceptable level at $60 \mathrm{kVp} / 40 \mathrm{mAs}(\mathbf{e})$

of scattered radiation in the thorax compared with the lumbar level, we would anticipate the dose in the thorax to be even lower.

The lower-contrast images of the cone-beam scanner are not comparable with a standard CT [4], but in the case of spinal surgery, spatial resolution is of greater concern. Dealing with very high-density material (bone and metal) relative to water, we showed that the needed spatial resolution can be obtained at a fraction of the preset exposure values (Table 2).

The parameters of the optimised protocols were to some extent dictated by limitations of the generator. Even at the lowest possible tube current $(10 \mathrm{~mA})$, all phantoms at all voltages above $90 \mathrm{kVp}$ showed acceptable image quality. If the $\mathrm{mA}$ were lowered further, a lower patient dose might have been achievable since the same dose at a higher $\mathrm{kVp}$ would result in a lower absorbed dose to the patient. Dose to the patient may have been reduced further by using a bowtie filter typically employed in standard CT scanners [38]. A preliminary study with such a filter has shown that dose may be additionally reduced by a factor of 2 . Automated current modulation as proposed by Kalender et al. [39] might also further reduce the dose as would adaptive statistical iterative reconstruction combined with conventional filtered back projection (a further estimated reduction of $30-40 \%$ [40]).
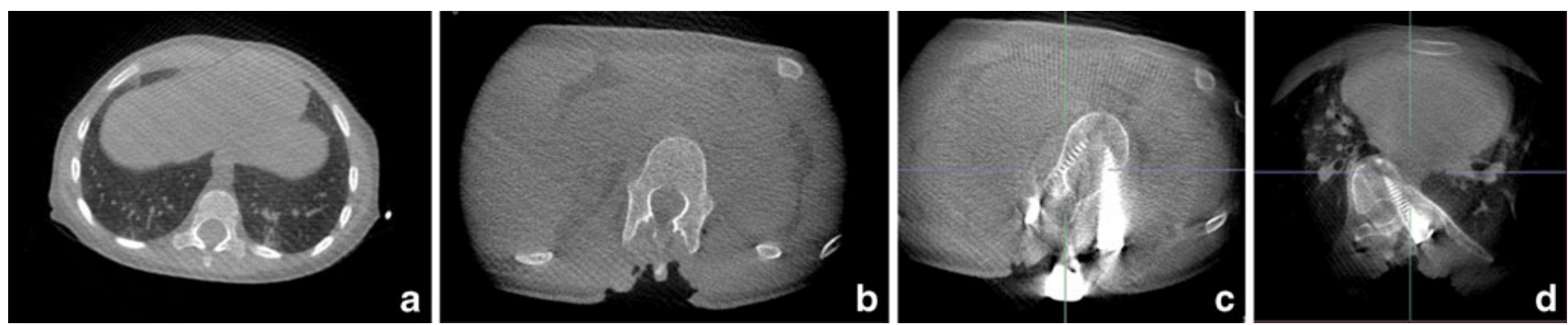

Fig. 5 Examples of intraoperative images with different dose settings with and without pedicle screws. a In a 2-year-old boy using $80 \mathrm{kVp} /$ $40 \mathrm{mAs}$ (16-cm protocol). b In a 14-year-old girl using $70 \mathrm{kVp} / 40 \mathrm{mAs}$ (24-cm protocol). c In a 14-year-old girl using $70 \mathrm{kVp} / 40 \mathrm{mAs}(24-\mathrm{cm}$ protocol), there are moderate to severe streak artifacts. $\mathbf{d}$ In a 17-yearold boy at $80 \mathrm{kVp} / 80 \mathrm{mAs}$, there is decreased metal artifacts compared to (c) at approximately $30 \%$ higher dose 


\section{Conclusion}

With optimised exposures at $70 \mathrm{kVp} / 40 \mathrm{mAs}$ for a 1-yearold-equivalent phantom, $70 \mathrm{kVp} / 80 \mathrm{mAs}$ for a 5 -year-oldequivalent phantom and $80 \mathrm{kVp} / 40 \mathrm{mAs}$ for a 12 -year-oldequivalent phantom, radiation doses for intraoperative 3-D imaging with a cone-beam flat-panel detector scanner were reduced at least $89 \%$ and could still be used to safely guide the placement of pedicle screws. The effective doses for optimised scans were estimated at approximately $0.5 \mathrm{mSv}$ and were between 91-94,5\% lower than the effective dose estimated for the manufacturers' default exposure values.

Open Access This article is distributed under the terms of the Creative Commons Attribution License, which permits any use, distribution, and reproduction in any medium, provided the original author(s) and the source are credited.

\section{References}

1. Doody MM, Lonstein JE, Stovall M et al (2000) Breast cancer mortality after diagnostic radiotherapy. Spine 25:2052-2063

2. Ronckers CM, Land CE, Miller JS et al (2010) Cancer mortality among women frequently exposed to radiographic examinations for spinal disorders. Radiat Res 174:83-90

3. Kalender WA, Kyriakou Y (2007) Flat-detector computed tomography (FD-CT). Eur Radiol 17:2767-2779

4. Tian NF, Xu HZ (2009) Image guided pedicle screw insertion accuracy: a metaanalysis. Int Orthop 18:341-346

5. Watkins RG IV, Gupta A, Watkins RG III (2010) Costeffectiveness of image-guided spine surgery. Open Orthop J 4:228-233

6. Atesok K, Finkelstein J, Khoury A et al (2007) The use of intraoperative three-dimensional imaging (ISO-C-3D) in fixation of intraarticular fractures. Int J Care 38:1163-1169

7. Zhang J, Weir V, Fajardo L et al (2009) Dosimetric characterization of a cone-beam O-arm ${ }^{\mathrm{TM}}$ imaging system. J Xray Sci Technol 17:305-317

8. Brenner DJ, Elliston CD, Hall EJ et al (2001) Estimated risk of radiation-induced fatal cancer from pediatric CT. AJR 176:289296

9. Mueller DL, Hatab M, Al-Senan R et al (2011) Pediatric radiation exposure during the initial evaluation for blunt trauma. J Trauma 70:724-731

10. National Electrical Manufacturers Association (2004) General guidelines for reducing CT pediatric dose through scan protocol adjustments. NEMA white paper, Rosslyn, VA, USA. www.nema.org

11. International Commission on Radiological Protection (2007) The 2007 recommendations of the International Commission on Radiological Protection. ICRP publication 103

12. Siegel J, Castellan NJ (1988) Nonparametric statistics for the behavioural sciences. McGraw-Hill, New York

13. Byrt T, Bishop J, Carlin B (1993) Bias prevalence and kappa. J Clin Epidemiol 46:423-429

14. Landis JR, Koch GG (1977) The measurement of observer agreement for categorical data. Biometrics 33:159-174
15. Li X, Zhang D, Liu B (2011) A practical approach to estimate the weighted CT dose index over an infinite integration length. Phys Med Biol 56:5789-5803

16. Dixon RL (2003) A new look at CT dose measurement: Beyond CTDI. Med Phys 30:1227-1280

17. Prevrhal S, Fox JC, Shepherd JA et al (2003) Accuracy of CTbased thickness measurement of thin structures: modelling of limited spatial resolution in all three dimensions. Med Phys $30: 1-8$

18. Khadilkar AV, Sanwalka NJ, Chiplonkar SA et al (2011) Normative data and percentile curves for dual energy x-ray absorptiometry in healthy Indian girls and boys aged 5-17 years. Bone 48:810-819

19. Shepherd JA, Wang L, Gilsanz V et al (2011) Optimal monitoring time between DXA measures in children. J Bone Miner Res 26:2745-2752

20. Wolf O, Ström H, Milbrink J et al (2009) Differences in hip bone mineral density may explain the hip fracture pattern in osteoarthritic hips. Acta Orthop 80:308-313

21. Penny JØ, Ovesen O, Brixen K et al (2010) Bone mineral density of the femoral neck in resurfacing hip arthroplasty. Precision of DXA biased by region of interest and rotation of hip. Acta Orthop $81: 318-323$

22. Kosmoupoulos V, Schizas C (2007) Pedicle screw placement accuracy: a meta-analysis. Spine 32:E111-E120

23. Ledonio CG, Vitale MG, Richards BS (2010) Meta-analysis of the safety and efficacy of pedicle screw spinal instrumentation in pediatric spinal deformity: Results of SRS and POSNA task force. Spine J 10:S4-S5

24. Abul-Kassim K, Strömbeck A, Ohlin A et al (2009) Reliability of low radiation dose $\mathrm{CT}$ in the assessment of screw placement after posterior scoliosis surgery evaluated with a new grading system. Spine 34:941-948. doi:10.1097/BSD.0b013e318211fdea

25. Silberman J, Riese F, Allam Y et al (2011) Computer tomography assessment of pedicle screw placement in lumbar and sacral spine: comparison between freehand and $\mathrm{O}$-arm based navigation techniques. Eur Spine J 20:875-881

26. Oertel MF, Hobart J, Stein M et al (2011) Clinical and methodological precision of spinal navigation assisted by $3 \mathrm{D}$ intraoperative O-arm radiographic imaging. J Neurosurg Spine 14:532-536

27. Larsson AN, Santos RG, Polly DW et al (2012) Pediatric screw placement using intraoperative CT and 3D image guided navigation. Spine (Phila Pa 1976) 37:E188-194. doi:10.1097/ BRS.0b013e31822a2e0a

28. Jones DP, Robertson PA, Lunt B et al (2000) Radiation exposure during fluoroscopically assisted pedicle screw insertion in the lumbar spine. Spine 25:1538-1541

29. Ul Haque M, Shufflebagger HL, O'Brien M et al (2006) Radiation exposure during pedicle screw placement in adolescent idiopathic scoliosis: is fluoroscopy safe? Spine 31:2516-2520

30. Rampersaud YR, Foley KT, Shen AC et al (2000) Radiation exposure to the spine surgeon during fluoroscopically assisted pedicle screw insertion. Spine 25:2637-2645

31. Slomczykowski M, Roberto M, Schneeberger P et al (1999) Radiation dose for pedicle screw insertion. Fluoroscopic method versus computer-assisted surgery. Spine 24:975-982

32. Zausinger S, Scheder B, Uhl E et al (2009) Intraoperative computed tomography with integrated navigation system in spinal stabilization. Spine 34:2919-2926

33. Beck M, Mittelmeier T, Gierer P et al (2009) Benefit and accuracy of intraoperative 3D-imaging after pedicle screw placement: a prospective study in stabilizing thoracolumbar fractures. Eur Spine J 18:1469-1477

34. Illés T, Tunyogi-Csapó M, Somoskeöy S (2011) Breakthrough in three-dimensional scoliosis diagnosis: significance of horizontal plane view and vertebra vectors. Eur Spine J 20:135-143 
35. Deschênes S, Charron G, Beaudoin G et al (2010) Diagnostic imaging of spinal deformities. Reducing patient radiation dose with a new slot-scanning X-ray imager. Spine 35:989-994

36. Abul-Kasim K, Söderberg M, Selariu E et al (2012) Optimization of radiation exposure and image quality of the cone-beam O-arm intraoperative imaging system in spinal surgery. J Spinal Disord Tech 25:52-58. doi:10.1097/BSD.0b013e318211fdea

37. Statens Institut for Strålehygiejne (2006) Børnedoser ved radiologi. Sundhedsstyrelsen, Copenhagen
38. Mail N, Moseley DJ, Siewerdsen JH et al (2009) The influence of bowtie filtration on cone-beam CT image quality. Med Phys $36: 22-32$

39. Kalender WA, Buchenau S, Deak P et al (2008) Technical approaches to the optimization of CT. Phys Med 24:71-79

40. Miéville FA, Gudinchet F, Rizzo E et al (2011) Paediatric cardiac CT examinations: impact of the iterative reconstruction method ASIR on image quality - preliminary findings. Pediatr Radiol 41:1154-1164 